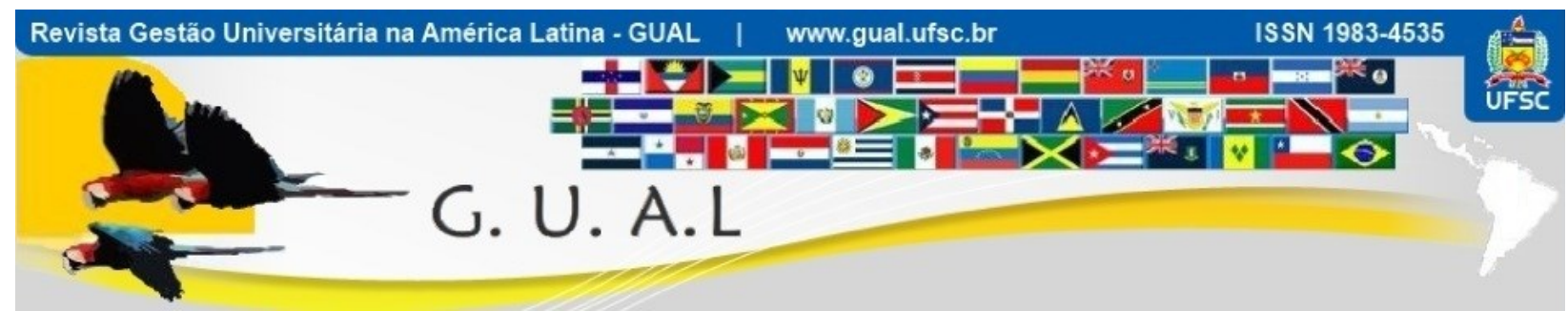

DOI: http://dx.doi.org/10.5007/1983-4535.2017v10n3p17

\title{
SISTEMAS DE CONTROLE E ALINHAMENTO ESTRATÉGICO: UMA ANÁLISE DO EQUILÍBRIO ENTRE AS ALAVANCAS DE SIMONS E O ALINHAMENTO COM A ESTRATÉGIA DE UMA INSTITUIÇÃO PÚBLICA DE ENSINO SUPERIOR
}

CONTROL SYSTEMS AND STRATEGIC ALIGNMENT: A BALANCE ANALYSIS BETWEEN SIMONS' LEVERS AND ITS ALIGNMENT WITH THE STRATEGY OF A PUBLIC HIGHER EDUCATION INSTITUTION

Thiago Cesar Bezerra Moreno, Mestre Universidade Estadual do Oeste do Paraná - UNIOESTE tmoreno2@gmail.com

Silvana Anita Walter, Doutora Universidade Estadual do Oeste do Paraná - UNIOESTE silvanaanita.walter@gmail.com

Elói Junior Damke, Doutor Universidade Estadual do Oeste do Paraná - UNIOESTE eloi.damke@gmail.com

Recebido em 10/fevereiro/2016

Aprovado em 19/maio/2017

Sistema de Avaliação: Double Blind Review

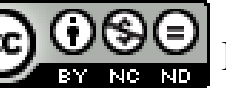

Esta obra está sob uma Licença Creative Commons Atribuição-Uso. 


\title{
RESUMO
}

Um número crescente de estudos tem buscado analisar a relação entre mecanismos de controle e alinhamento estratégico. Contudo, são raros os estudos que avaliam esta relação em instituições públicas de ensino superior, em especial, fazendo uso dos mecanismos de controle propostos por Simons (1995). Diante disso, o objetivo deste estudo é avaliar o equilíbrio das alavancas de controle - propostas por Simons (1995) -, identificando o alinhamento dos controles com os objetivos estratégicos de implantação da UNILA - Universidade Federal da Integração Latino-Americana. Dados levantados por meio de survey, com indicadores operacionais extraídos da escala proposta por Damke et al. (2011), e analisados por meio de estatísticas descritivas e correlações, revelaram a presença equilibrada das alavancas na instituição pesquisada e correlação significativa com a variável alinhamento estratégico. Pela análise, foi possível concluir que os indicadores operacionais são qualificados para avaliarem o alinha $\neg$ mento estratégico e, também, que a instituição apresenta a presença equilibrada das alavancas.

Palavras chave: Alinhamento estratégico. Sistemas de controle. Alavancas de Simons.

\begin{abstract}
A growing number of studies has sought to analyze assessed the relationship between control mechanisms and strategic alignment. However, the studies that evaluate this relation in public institutions of higher education are scarce, in particular making use of the proposed control mechanisms by Simons (1995). Thus, the objective of this study is to assess the balance of the levers of control - proposed by Simons (1995) -, identifying the alignment of the controls with the strategic objectives of deployment of UNILA - Universidade Federal da Integração Latino-Americana. Data collected through survey research, with operational indicators extracted from the scale proposed by Damke et al. (2011), and analyzed through descriptive statistics and correlations, revealed a balanced presence of the levers in the institution and significant correlation with the strategic alignment variable. For the analisis, is was possible to conclude that the operational indicators are qualified to evaluate the strategic alignment and that the institution offers balanced levers.
\end{abstract}

Keywords: Strategic alignment. Control systems. Simons' Levers. 


\section{SISTEMAS DE CONTROLE E ALINHAMENTO ESTRATÉGICO: UMA ANÁLISE DO EQUILÍBRIO \\ ENTRE AS ALAVANCAS DE SIMONS E O ALINHAMENTO COM A ESTRATÉGIA DE UMA INSTITUIÇÃO PÚBLICA DE ENSINO SUPERIOR \\ DOI: http://dx.doi.org/10.5007/1983-4535.2017v10n3p17}

\section{INTRODUÇÃO}

As instituições públicas têm o dever legal de atingir seus objetivos, primando pela eficiência nos resultados. O planejamento estratégico contribui para essa finalidade. A contabilidade gera diversos dados que são convertidos em controles financeiros. Esses controles tradicionais são utilizados na tomada de decisões, porém no contexto estratégico, surge a necessidade de ir além da visão econômico-financeira.

Os sistemas de controle, quando alinhados, permitem mudanças na estrutura organizacional que possibilitam manter o planejamento. Anthony e Govindarajan (2001) observam que o controle gerencial é a ferramenta que os executivos utilizam para monitorar outros membros da organização e tem ainda a finalidade de garantir que as estratégias sejam obedecidas, viabilizando atingir os objetivos da organização.

O controle é uma característica inata da natureza humana. Nesse sentido, as pesquisas sobre essa temática sempre estiveram alinhadas com os estudos organizacionais. Cintra (2011), em sua tese, salienta que há consenso na afirmação de que os processos de controle são parte fundamental das atividades organizacionais. Simons (1995) adota a definição de sistemas de controle gerencial como sendo sistemas de informação que os gerentes utilizam para manter organizadas as rotinas institucionais. O autor ainda afirma que os controles são executados de diversas maneiras - desde feedback até controles sociais e culturais.

Esta pesquisa em particular adotou como base o modelo de alavancas de controle (MAC) proposto por Simons (1995), que considerou quatro conceitos-chave: valores centrais; riscos a serem evitados; incertezas estratégicas e variáveis críticas de desempenho. Os conceitos são operacionalizados por sistemas - sistemas de crenças; sistemas de limites; sistemas de controles diagnósticos e sistemas de controles interativos -, denominados alavancas de controle.

Os sistemas de controle precisam balancear as demandas concorrentes, a exemplo de: liberdade e restrição, experimentação e eficiência. As alavancas criam forças opostas (positivas e negativas) que equilibram as demandas. A utilização de um sistema de controle não alinhado aos objetivos estratégicos da organização pode dificultar o alcance dos seus objetivos.

No caso da instituição proposta, um sistema de controle, com enfoque em restrições (forças negativas), pode conduzir à perda de oportunidades. O sistema tem extremos em 


\section{SISTEMAS DE CONTROLE E ALINHAMENTO ESTRATÉGICO: UMA ANÁLISE DO EQUILÍBRIO \\ ENTRE AS ALAVANCAS DE SIMONS E O ALINHAMENTO COM A ESTRATÉGIA DE UMA INSTITUIÇÃO PÚBLICA DE ENSINO SUPERIOR \\ DOI: http://dx.doi.org/10.5007/1983-4535.2017v10n3p17}

forças positivas, que podem levar a ideias ou projetos eficientes - embora tenham pouca relação com os objetivos estratégicos. A proposta de Simons é explicitar o uso de controles tradicionais dos objetivos simultaneamente com controles sócio comportamentais (CINTRA, 2010).

Espera-se que, a partir da avaliação com os indicadores propostos por Damke, Silva e Walter (2011), a pesquisa identifique o grau com que cada uma das alavancas de controle é utilizada no momento estratégico de implantação. E também que a instituição possa implantar esses indicadores, possibilitando avaliações longitudinais. Essa problemática deu origem às seguintes questões: Qual o grau em que cada uma das alavancas de controle, propostas por Simons (1995), estão presentes na Universidade Federal da Integração Latino-Americana (UNILA)?

Assim, para a consecução desta problemática, o artigo está estruturado em quatro seções adicionais à essa introdução. Na próxima seção, apresenta-se uma síntese acerca da base teórica sobre sistemas de controle, eixo teórico central desse estudo. Em seguida, são apresentados os procedimentos de pesquisa adotados, antecedendo a seção de descrição e análise dos resultados. Por fim, na última seção conclui-se o artigo com considerações finais, contribuições e sugestões para pesquisas futuras.

\section{FUNDAMENTAÇÃO TEÓRICA}

Segundo a proposta de Otley (1999), consideram-se sistemas de controle estratégico: Balanced Scorecard (BSC); o Orçamento; o Economic Value Added (EVA); o Gerenciamento pelas Diretrizes (AKAO, 1997) e as Alavancas de Controle (SIMONS, 1995). Para este estudo, utilizou-se apenas o último, demonstrando quais características justificam sua utilização. Na revisão teórica, busca-se conceituar controle estratégico e o valor público gerado pelo alinhamento dos controles com os objetivos estratégicos.

\subsection{CONTROLE ESTRATÉGICO}

O cenário não é estático e a estratégia precisa acompanhar as mudanças. Muitas escolhas perdem sentido ao longo do tempo, ou seja, o que deu certo em determinadas circunstâncias, pode falhar em outros contextos (DUCLÓS; SANTANA, 2004). Em função dessa dinâmica, o processo de formulação da estratégia torna-se complexo e precisa ser monitorado, para possibilitar o alinhamento estratégico. 


\section{SISTEMAS DE CONTROLE E ALINHAMENTO ESTRATÉGICO: UMA ANÁLISE DO EQUILÍBRIO \\ ENTRE AS ALAVANCAS DE SIMONS E O ALINHAMENTO COM A ESTRATÉGIA DE UMA INSTITUIÇÃO PÚBLICA DE ENSINO SUPERIOR \\ DOI: http://dx.doi.org/10.5007/1983-4535.2017v10n3p17}

As alavancas de Controle de Simons permitem avaliar aspectos temporalmente diferentes e causas e efeitos, tendo como finalidade informar o desempenho dos seus processos, principalmente os estratégicos.

No setor público, avaliar o desempenho tem se mostrado uma tarefa árdua, em razão de diversas barreiras, a exemplo da estabilidade no emprego, ministérios com grande quantidade de indivíduos, falta de orçamento, cultura, ausência de comparabilidade de mercado. O modelo teórico proposto por Simons (1995), torna-se adequado para uma instituição pública, à medida que possibilita avaliar aspectos práticos e teóricos do alinhamento dos controles estratégicos, sem ter como enfoque central vantagem competitiva e lucratividade. Nesse sentido, Schreyogg e Steimann (1987) ensinam que o controle estratégico é um processo que tem como objetivo avaliar se os planos estratégicos estão calibrados com os objetivos da instituição, em um determinado período de tempo.

Considerando as condições de mudanças estratégicas, Simons (1995) enfatiza que a estrutura e os sistemas de controle permitem formalizar crenças, estabelecer fronteiras, medir variáveis críticas, motivar a avaliação acerca das incertezas estratégicas. Infere-se que os controles não têm a finalidade de estabelecer limitações, e sim horizontes os quais se busca atingir - um princípio que oferece uma importante diferença entre o temor de estar abaixo do limite e a motivação de se aproximar das fronteiras.

Com base nas ponderações acima mencionadas, percebe-se que um sistema de controle coerente com a estratégia e a estrutura torna-se relevante para promover ações favoráveis ao aprendizado e à motivação, e que permitam a sustentação dos objetivos planejados (DAMKE et al., 2011). Os controles precisam estabelecer horizontes, a partir dos quais as ações se tornem seguras, principalmente diante dos riscos que os indivíduos não estão dispostos a correr. No serviço público, o agente alheio a seus limites está suscetível a evitar uma ação nova, que poderia melhorar o desempenho da instituição.

Conclui-se que os indicadores têm a finalidade de informar as organizações sobre a eficiência de seus processos. Se forem elaborados inapropriadamente, podem levar a resultados não reais e, consequentemente, gerar tomadas de decisão inadequadas (DAMKE et al., 2011). Os gerentes de topo utilizam as informações para vários fins: sinalizar o domínio no qual os subordinados devem procurar oportunidades; comunicar planos e objetivos e vigiar a consecução. É nesse contexto que reside a importância das alavancas propostas por Simons (1995). 


\subsection{SISTEMAS DE CONTROLE: O MODELO DA ALAVANCAS DE SIMONS}

O sistema de controle proposto por Simons (1995), nos anos 90, tem como finalidade a implementação e o monitoramento das estratégias da organização, que passa pela consideração de quatro conceitos-chave: valores centrais; riscos a serem evitados; incertezas estratégicas e variáveis críticas de desempenho. Os conceitos são acessados por meio da operacionalização de quatro sistemas, denominados alavancas de controle, apresentados no Quadro 1.

Quadro 1 Definição das Alavancas de Controle de Simons

\begin{tabular}{|l|l|}
\hline \multicolumn{1}{|c|}{ Alavanca } & \multicolumn{1}{c|}{ Definição } \\
\hline $\begin{array}{l}\text { Sistemas de } \\
\text { crenças }\end{array}$ & $\begin{array}{l}\text { São as definições institucionais que a organização usa para comunicar formalmente e } \\
\text { enfatizar sistematicamente os valores, propósito e direção. Essas definições } \\
\text { demonstram aos subordinados a direção e quais os valores centrais a gestão pretende } \\
\text { que sejam seguidos, que estão, por sua vez, ligados à estratégia da empresa. } \\
\text { Objetivam inspirar e motivar os indivíduos a buscar, explorar, criar e se engajar em } \\
\text { ações apropriadas na organização - sendo, portanto, de caráter positivo. Podem } \\
\text { aparecer em instrumentos tais como missão, visão, credos e outros. }\end{array}$ \\
\hline $\begin{array}{l}\text { Sistemas de } \\
\text { limites }\end{array}$ & $\begin{array}{l}\text { Impõem limites na busca de oportunidades por parte da organização. Nesse sentido, } \\
\text { são negativos, restringem o comportamento dos indivíduos. Em ambientes de } \\
\text { negócio dinâmicos, é necessário estabelecer fronteiras aos empregados, para impedi- } \\
\text { los de se engajarem em comportamentos de risco elevado. Esses sistemas delimitam o } \\
\text { domínio estratégico aceitável para a atividade dos participantes organizacionais e } \\
\text { comunicam as ações a serem evitadas, com o objetivo de dar liberdade de ação, } \\
\text { dentro de determinados limites pré-definidos. }\end{array}$ \\
\hline $\begin{array}{l}\text { Sistemas de } \\
\text { controles } \\
\text { diagnósticos }\end{array}$ & $\begin{array}{l}\text { É o pilar do controle gerencial tradicional e objetiva motivar os empregados a } \\
\text { desempenharem e alinharem seu comportamento com os objetivos organizacionais. } \\
\text { São sistemas que a gestão utiliza para monitorar os resultados e corrigir desvios dos } \\
\text { padrões esperados de desempenho. }\end{array}$ \\
\hline $\begin{array}{l}\text { Sistemas de } \\
\text { controles } \\
\text { interativos }\end{array}$ & $\begin{array}{l}\text { Estimulam o aprendizado e a busca de oportunidades, permitindo, portanto, novas } \\
\text { estratégias emergirem, quando os participantes reagirem às oportunidades e ameaças } \\
\text { percebidas. Operam, estimulando e fazendo com que a organização se mantenha } \\
\text { alerta, "viva". }\end{array}$ \\
\hline
\end{tabular}

Fonte: (CINTRA, 2011)

O modelo proposto, portanto, supõe que os gerentes controlem as estratégias, por meio do uso das quatro alavancas básicas. Essas alavancas possibilitam inúmeras variáveis opera $\neg$ cio-nais, que irão compor o total de indicadores de desempenho do planejamento estratégico. Estas quatro alavancas criam forças opostas, denominadas yin e yang, que, ao mesmo tempo, impul $\neg$ sionam e mantêm a implementação da estratégia eficaz. Na filosofia 
chinesa, as forças positivas e negativas se opõem e cuja fusão cria o mundo como nós o conhecemos (SIMONS, 1995).

Figura 1 Modelo teórico do sistema de controle estratégico de Simons (1995)

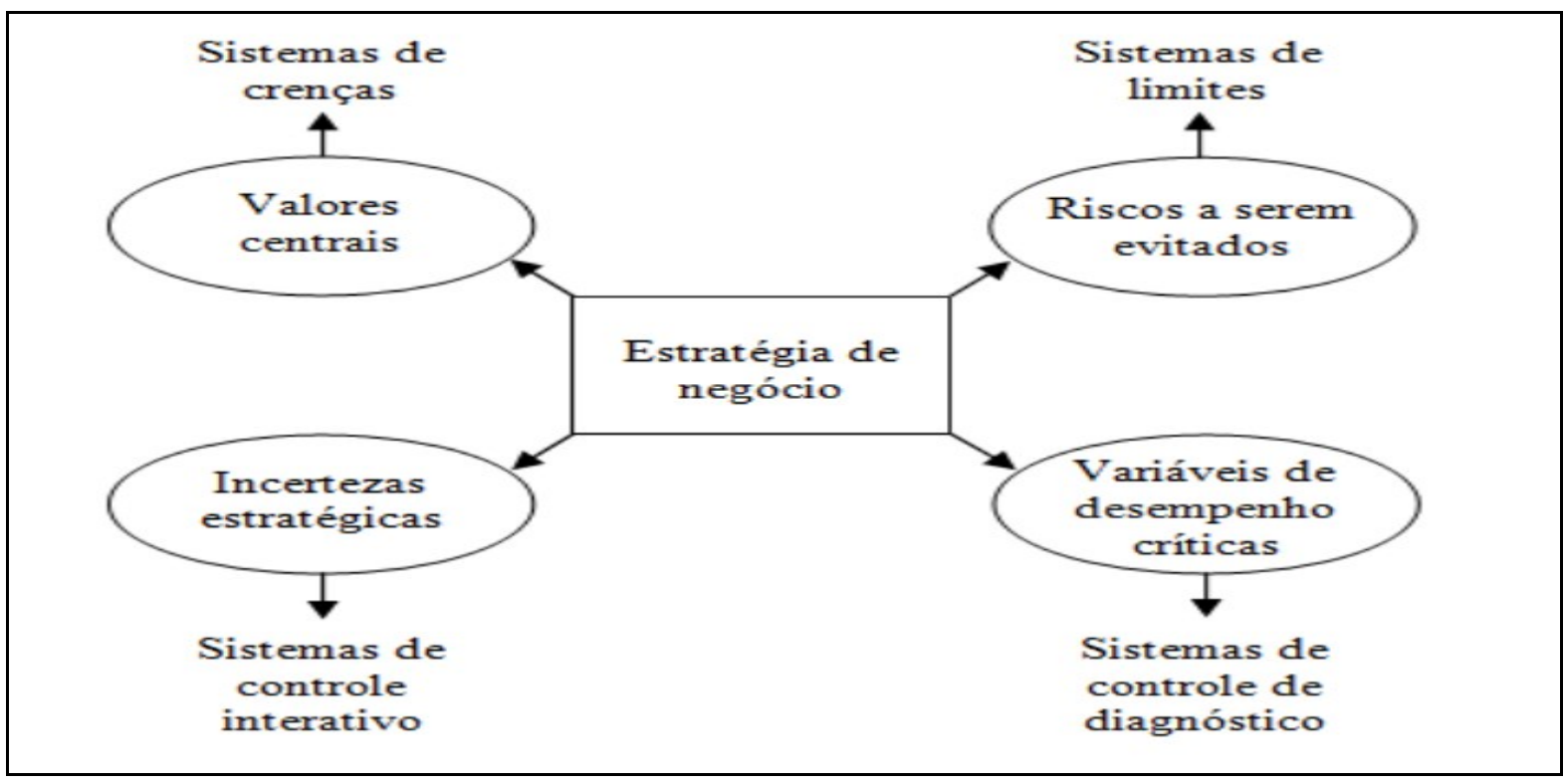

Fonte: Simons (1995)

O equilíbrio das forças é um forte pressuposto de alinhamento dos controles com os objetivos estratégicos. As alavancas Crença e Controles Interativos oferecem forças positivas inspiradoras. Em contraponto, os controles de Diagnósticos e de Sistemas de Limites funcionam como forças negativas, que criam restrições e limites de atitudes. Nesse contexto, baseado no modelo teórico apresentado na figura 1 , espera-se que a instituição apresente a percepção das quatro alavancas de maneira equilibrada.

\subsection{ALINHAMENTO ESTRATÉGICO E VALOR PÚBLICO}

Para este estudo, considerou-se que a criação de valor público é um elemento-chave da política pública moderna e, portanto, desejável. No entanto, não há consenso na definição do que é valor público. A literatura sobre valor público tem sido desenvolvida por Mark Moore (1995), na Escola Kennedy de Governo, nos EUA, que afirmou em seu texto seminal Criação de Valor Público, que gestores públicos devem buscar "produzir valor público".

As definições, geralmente, se dividem em um dos dois grupos: os que exploram valor público como um meio de gestão do setor público e aqueles que consideram a relação entre o valor público e medição de desempenho (BUSHFIELD, 2011). 


\section{SISTEMAS DE CONTROLE E ALINHAMENTO ESTRATÉGICO: UMA ANÁLISE DO EQUILÍBRIO \\ ENTRE AS ALAVANCAS DE SIMONS E O ALINHAMENTO COM A ESTRATÉGIA DE UMA INSTITUIÇÃO PÚBLICA DE ENSINO SUPERIOR \\ DOI: http://dx.doi.org/10.5007/1983-4535.2017v10n3p17}

Damke et al. (2011) observam que toda empresa tem como último objetivo ampliar o Market Value Added (MVA) e, pode-se considerar, que este indicativo reflete, de certa forma, o eficaz gerenciamento da organização a longo prazo. No entanto, no setor público, não há resultados comparáveis para retorno aos acionistas e nenhum dispositivo, como o mecanismo de preços, que pode informar o valor das organizações. Entretanto, independentemente do valor de mercado, o melhor desempenho possível com o menor orçamento é obrigação constitucional de qualquer instituição pública brasileira.

Kravchuk e Schack (1996) ressaltam que, ao final dos anos 1980, tornou-se evidente, em todos os setores, o interesse na prática de um ambiente de gestão eficaz. Para tal, é necessária a implantação de um sistema de medição de desempenho, com controle de medidas apropriado, que assegure o alinhamento das atividades e reflita no alcance do objetivo maior da organização.

O alinhamento estratégico tem como base os atributos dos estudos de Labovictz e Rosanski (1997), que declaram que as instalações precisam atender à missão, visão e objetivos. De acordo com os achados de Akim (2015) a produção intelectual, no campo da medição de desempenho na gestão pública, iniciou-se na década de 80 . No aspecto desempenho, o setor público precisa constantemente inovar seus processos internos e estruturas, para oferecer novas soluções e serviços. Nessa linha, o estudo de Beuren e Oro (2014) concluiu que existem evidências consistentes de que o desenho dos sistemas de controle gerenciais tem relação com a estratégia de diferenciação e inovação de produtos. Por fim, o alinhamento estratégico é conduzido por meio de um sistema de controle, que possibilite informações a fim de auxiliar na tomada de decisão. Os indicadores, produzidos por esses controles, permitem aos gestores detectar os desvios e manter o planejamento da instituição.

\section{DELINEAMENTO METODOLÓGICO}

Esta pesquisa classifica-se quanto aos objetivos como descritiva (RAUPP; BEUREN, 2009), pois visa caracterizar as práticas gerenciais adotadas pelas empresas objeto de estudo. Quanto à abordagem do problema, esta pesquisa caracteriza-se como quantitativa, visto que empregaram-se técnicas estatísticas na coleta e análise dos dados (RAUPP; BEUREN, 2009). Os levantamentos se tornam muito mais adequados para estudos descritivos, ensina Gil (2009). Nesse sentido, adotou-se o método survey como procedimento de pesquisa. 


\section{SISTEMAS DE CONTROLE E ALINHAMENTO ESTRATÉGICO: UMA ANÁLISE DO EQUILÍBRIO \\ ENTRE AS ALAVANCAS DE SIMONS E O ALINHAMENTO COM A ESTRATÉGIA DE UMA INSTITUIÇÃO PÚBLICA DE ENSINO SUPERIOR \\ DOI: http://dx.doi.org/10.5007/1983-4535.2017v10n3p17}

A população da pesquisa corresponde a 487 servidores técnico-administrativos em exercício e a amostra alcançou 155 respondentes. O questionário foi elaborado por meio do formulário eletrônico Formulários Google ${ }^{\complement}$ e divulgado no grupo dos técnicos administrativos da rede social Facebook e no informativo circular interno.

Utilizou-se como referência definições operacionais propostas por Damke et al. (2011). A adaptação resultou em 39 questões, sendo 9 para cada alavanca e 3 relacionadas aos atributos de alinhamento estratégico. Adotou-se a escala de 7 pontos, por oferecer maior precisão sobre a opinião do respondente. De modo geral, Selltiz et al. (2004) reconhece que, para que obtenhamos dados objetivos, uma escala precisa ser balanceada.

Optou-se pela técnica de amostragem, por conveniência não probabilística, orientada por Malhotra (2006). Disponibilizou-se o acesso a todos os servidores da instituição, com o objetivo de atingir o maior número de participantes. Porém, como limitação, a técnica não possibilita inferências que possam ser generalizadas para a população, em razão principalmente de representar a percepção de indivíduos com disposição para participar. Embora não probabilística, a amostra atende aos critérios estabelecidos por Hair et al. (2005), de que devem haver no mínimo 5 observações por variável de pesquisa.

Para viabilizar a análise dos indicadores em relação à percepção do alinhamento estratégico, realizaram-se: teste de confiabilidade de escala e redução de dimensão, por meio de análise fatorial e método de extração - análise de Componente Principal. Como último passo, realizam-se correlações não paramétricas ( $r o ̂$ de Spearman), que possibilitam a análise da correlação entre os indicadores propostos. Todos os testes estatísticos foram realizados no software estatístico SPSS 22.

\section{ANÁLISE E APRESENTAÇÃO DOS RESULTADOS}

Para verificar a presença de cada alavanca, utilizou-se a estatística descritiva. Como base para validar os indicadores, foram realizados testes de correlação entre as variáveis e teste de confiabilidade de escala, por meio do teste Alfa de Cronbah, apresentado na Tabela 1. 


\section{SISTEMAS DE CONTROLE E ALINHAMENTO ESTRATÉGICO: UMA ANÁLISE DO EQUILÍBRIO \\ ENTRE AS ALAVANCAS DE SIMONS E O ALINHAMENTO COM A ESTRATÉGIA DE UMA INSTITUIÇÃO PÚBLICA DE ENSINO SUPERIOR \\ DOI: http://dx.doi.org/10.5007/1983-4535.2017v10n3p17}

Tabela 1 Teste de confiabilidade de escala

\begin{tabular}{lccc}
\hline \multicolumn{1}{c}{ Dimensões } & $\begin{array}{c}\text { Alfa de } \\
\text { Cronbach }\end{array}$ & $\begin{array}{c}\text { Alfa de Cronbach com base } \\
\text { em itens padronizados }\end{array}$ & No de Indicadores \\
\hline Sistemas de Limites & 0,906 & 0,905 & 9 \\
Sistemas de Diagnóstico & 0,902 & 0,903 & 9 \\
Sistemas Interativos & 0,900 & 0,902 & 9 \\
Sistemas de Crenças & 0,919 & 0,920 & 9 \\
Alinhamento Estratégico & 0,688 & 0,686 & 3 \\
\hline
\end{tabular}

O coeficiente de Alfa de Cronbach é uma medida que varia de 0 a 1, utilizado para estimar a confiabilidade de um questionário aplicado em uma pesquisa. Um mínimo aceitável para esse coeficiente é 0,7 porém mais baixos podem ser aceitáveis, dependendo da pesquisa (HAIR et al., 2005). O teste de confiabilidade sugeriu que a exclusão do indicador (os serviços prestados pela instituição são reconhecidos como de qualidade pelos alunos, pesquisadores e comunidade externa) elevaria o Alfa para 0,705 , porém, optou-se pela manutenção do indicador, por não prejudicar as conclusões do estudo.

Diferentes níveis de controle levam a distintos níveis de alinhamento estratégico. A primeira etapa da análise apresenta a descrição dos dados de cada alavanca, com o propósito de identificar o grau em que as alavancas de controle estratégico estão presentes na instituição, a partir da percepção de seus servidores técnicos.

\subsection{ALAVANCAS DE FORÇAS POSITIVAS}

Diversos estudos apontam que os controles estratégicos produzem estímulos para que os objetivos sejam atingidos. Esses estímulos têm características positivas e negativas, e ainda que possam ser implantados de forma independente, precisam estar equilibrados. As organizações são criadas para alcançar objetivos específicos, mas também são sistemas sociais, ou seja, grupos unidos para atender necessidades pessoas e sociais. As organizações também são um conjunto de relações entre participantes autointeressados, em que cada um estabelece um equilíbrio entre o bem-estar social e as necessidades organizacionais (SIMONS, 1995).

A UNILA é uma autarquia federal, criada por lei, que estabelece objetivos a serem atingidos (BRASIL, 2010). O primeiro indicador da avaliação dos sistemas de crença encerra a divulgação da missão e visão a todos os integrantes. Embora o indicador tenha apresentado uma média de 3,76 , que está abaixo do nível (não concordo nem discordo), o grau que mais 


\section{SISTEMAS DE CONTROLE E ALINHAMENTO ESTRATÉGICO: UMA ANÁLISE DO EQUILÍBRIO ENTRE AS ALAVANCAS DE SIMONS E O ALINHAMENTO COM A ESTRATÉGIA DE UMA INSTITUIÇÃO PÚBLICA DE ENSINO SUPERIOR DOI: http://dx.doi.org/10.5007/1983-4535.2017v10n3p17}

apareceu foi 5 (concordo parcialmente), representado na coluna moda da Tabela 2. O resultado, na dimensão do sistema de crenças, indica que divulgar no site institucional não é suficiente para que a informação seja percebida pelos indivíduos da instituição.

Tabela 2 Estatística descritiva do indicador positivo sistemas de crenças

\begin{tabular}{l|c|c|c|c|c|c}
\multicolumn{1}{c|}{ Sistemas de Crenças } & \multicolumn{2}{c|}{$\begin{array}{c}\text { Total da } \\
\text { Amostra }\end{array}$} & \multicolumn{2}{c|}{$\begin{array}{c}\text { Menos de 18 } \\
\text { meses }\end{array}$} & \multicolumn{2}{c}{$\begin{array}{c}\text { Mais de 18 } \\
\text { meses }\end{array}$} \\
\cline { 2 - 7 } & Média & Moda & Média & Moda & Média & Moda \\
\hline $\begin{array}{l}\text { 1. A visão e a missão da organização são } \\
\text { divulgadas para todos os integrantes da } \\
\text { organização. }\end{array}$ & 3,76 & 5 & 3,63 & 5 & 3,91 & 5 \\
\hline $\begin{array}{l}\text { 2. A organização possui crenças (aspectos } \\
\text { em que acredita e confia) difundidas entre } \\
\text { seus integrantes. }\end{array}$ & 3,78 & 5 & 3,66 & 5 & 3,91 & 5 \\
\hline $\begin{array}{l}\text { 3. A visão, a missão e as crenças da } \\
\text { organização são claras. }\end{array}$ & 3,61 & 5 & 3,54 & 4 & 3,69 & 5 \\
\hline $\begin{array}{l}\text { 4. Essas crenças compartilhadas descrevem } \\
\text { os valores fundamentais defendidos pela } \\
\text { organização. }\end{array}$ & 3,71 & 4 & 3,58 & 4 & 3,85 & 5 \\
\hline $\begin{array}{l}\text { 5. Essas crenças fornecem orientações sobre } \\
\text { os propósitos da organização (direções que } \\
\text { ela deseja seguir). }\end{array}$ & 3,77 & 5 & 3,73 & 4 & 3,81 & 5 \\
\hline $\begin{array}{l}\text { 6. Essas crenças fornecem orientações sobre } \\
\text { os comportamentos a serem realizados na } \\
\text { busca de oportunidades para a organização. }\end{array}$ & 3,79 & 4 & 3,84 & 4 & 3,73 & 5 \\
\hline $\begin{array}{l}\text { 7. Essas crenças da organização servem } \\
\text { como pano de fundo (base) para a definição } \\
\text { de estratégias. }\end{array}$ & 3,84 & 5 & 3,71 & 4 & 3,97 & 5 \\
\hline $\begin{array}{l}\text { 8. Essas crenças da organização auxiliam na } \\
\text { busca pelo alcance execução das } \\
\text { estratégias. }\end{array}$ & 3,79 & 5 & 3,84 & 4 & 3,75 & 5 \\
\hline $\begin{array}{l}\text { 9. Essas crenças da organização contribuem } \\
\text { em momentos de mudança, norteando o que } \\
\text { a organização busca. }\end{array}$ & 3,81 & 5 & 3,83 & 4 & 3,79 & 5 \\
\hline
\end{tabular}

Fonte: Indicadores adaptados de Damke et al. (2011)

Na Tabela 2, observam-se todos os indicadores com média próxima ao nível 4 (não concordo nem discordo) e que as médias entre os grupos (mais de 18 meses) e (menos de 18 meses), referentes ao tempo de serviço na instituição, estão praticamente no mesmo nível. Porém, o grupo que tem mais de 18 meses apresentou moda no nível 5 (concordo parcialmente). Percebe-se, portanto, por este último nível, a indicação de insegurança sobre as definições quanto ao direcionamento dos subordinados e quais valores centrais a gestão pretende que sejam seguidos. 


\section{SISTEMAS DE CONTROLE E ALINHAMENTO ESTRATÉGICO: UMA ANÁLISE DO EQUILÍBRIO ENTRE AS ALAVANCAS DE SIMONS E O ALINHAMENTO COM A ESTRATÉGIA DE UMA INSTITUIÇÃO PÚBLICA DE ENSINO SUPERIOR \\ DOI: http://dx.doi.org/10.5007/1983-4535.2017v10n3p17}

Tabela 3 Estatística descritiva dos indicadores positivos

\begin{tabular}{|c|c|c|c|c|c|c|}
\hline \multirow[t]{2}{*}{ Sistemas Interativo } & \multicolumn{2}{|c|}{$\begin{array}{l}\text { Total da } \\
\text { Amostra }\end{array}$} & \multicolumn{2}{|c|}{$\begin{array}{l}\text { Menos de } 18 \\
\text { meses }\end{array}$} & \multicolumn{2}{|c|}{$\begin{array}{l}\text { Mais de } 18 \\
\text { meses }\end{array}$} \\
\hline & Média & Moda & Média & Moda & Média & Moda \\
\hline $\begin{array}{l}\text { 1. Os superiores, frequentemente, envolvem } \\
\text { os subordinados em atividades de gestão. }\end{array}$ & 4,01 & 5 & 3,81 & 5 & 4,21 & 5 \\
\hline $\begin{array}{l}\text { 2. Os gestores convidam os servidores para } \\
\text { participarem da tomada de decisão em } \\
\text { momentos importantes. }\end{array}$ & 3,70 & 5 & 3,69 & 5 & 3,72 & 5 \\
\hline $\begin{array}{l}\text { 3. Costumeiramente, os superiores agendam } \\
\text { reuniões face a face. }\end{array}$ & 4,43 & 5 & 4,40 & 6 & 4,47 & 5 \\
\hline $\begin{array}{l}\text { 4. Opiniões de servidores já produziram } \\
\text { mudanças importantes e positivas na } \\
\text { organização. }\end{array}$ & 4,90 & 6 & 4,71 & 6 & 5,09 & 5 \\
\hline $\begin{array}{l}\text { 5. Os gestores incentivam o aparecimento } \\
\text { de novas iniciativas dos servidores. }\end{array}$ & 4,41 & 5 & 4,55 & 5 & 4,27 & 5 \\
\hline $\begin{array}{l}\text { 6. Existe, formalmente, um momento ou } \\
\text { maneira para que os servidores colaborem } \\
\text { com opiniões sobre oportunidades para a } \\
\text { organização. }\end{array}$ & 3,88 & 5 & 3,85 & 5 & 3,91 & 5 \\
\hline $\begin{array}{l}\text { 7. Os gestores despertam a atenção dos } \\
\text { servidores para as incertezas estratégicas, } \\
\text { estimulando-os para resolvê-las. }\end{array}$ & 3,60 & 4 & 3,68 & 2 & 3,52 & 4 \\
\hline $\begin{array}{l}\text { 8. A participação dos servidores com } \\
\text { sugestões é importante para que as } \\
\text { estratégias foquem a organização como um } \\
\text { todo. }\end{array}$ & 5,17 & 6 & 5,26 & 6 & 5,07 & 7 \\
\hline $\begin{array}{l}\text { 9. Os gestores procuram estimular o } \\
\text { aprendizado organizacional por meio do } \\
\text { compartilhamento de experiências e } \\
\text { percepções entre os servidores. }\end{array}$ & 4,01 & 5 & 4,24 & 5 & 3,77 & 5 \\
\hline
\end{tabular}

Fonte: Indicadores adaptados de Damke et al. (2011)

$\mathrm{Na}$ análise do sistema interativo, Tabela 3, observa-se que, quando o aspecto de interação está relacionado com o gestor, o indicador médio foi o nível não concordo nem discordo. Mas, em relação à percepção da importância da participação dos servidores com sugestões, o nível de percepção atingiu média de 5,17 sendo que a opção mais frequente foi concordo totalmente, ou seja, na percepção dos respondentes, a interação dos servidores com a estratégia é importante, mas a percepção da interação com os gestores pode ser desenvolvida.

Como a instituição está em fase de implantação, com 5 anos desde a criação, os indicadores apresentam sinais para implementação de medidas construtivas, não sendo objetivo desta análise avaliar as razões sobre os resultados. 


\subsection{ALAVANCAS DE FORÇAS NEGATIVAS}

Os controles gerenciais tradicionais objetivam motivar os empregados a desempenharem e alinharem seu comportamento com os objetivos organizacionais. São sistemas que a gestão utiliza para monitorar os resultados. A percepção da presença desses controles pode alterar o comportamento dos indivíduos em relação aos objetivos estratégicos. $\mathrm{Na}$ tabela 4 apresentam-se os indicadores dos sistemas de controle de diagnóstico e na tabela 5 os resultados do sistema de limites.

Antes de analisar os indicadores negativos, é necessário esclarecer dois pontos: 1) o código de ética adotado pela instituição é formalmente divulgado no ato da entrada em exercício de cada servidor, portanto é obrigatório para todos os servidores públicos federais declarar ter ciência destas diretrizes; 2) os órgãos de controle externo monitoram os resultados, impulsionando os gestores a produzirem informações.

Tabela 4 Estatística descritiva dos indicadores negativos sistemas de diagnóstico

\section{Sistemas de Diagnóstico}

1. A organização possui sistemas de monitoramento de resultados, ou seja, os gestores monitoram, efetiva e periodicamente, os resultados atingidos.

2. Costumeiramente, são utilizados inúmeros controles internos na organização, visando monitorar as atividades.

3. A organização possui metas e objetivos claros.

4. Essas metas e objetivos da organização são, efetiva e periodicamente, monitorados, para verificar se estão sendo atingidos.

5. A organização possui planejamento formalmente divulgado.

6. Os superiores avaliam se esse planejado foi atingido.

7. A organização avalia o comportamento de cada responsável pelas metas individuais.

8. Em casos de não atendimento pleno da meta, a organização penaliza os servidores.

9. Os superiores negociam as metas com os servidores, com base nos relatórios e nos controles internos.

\begin{tabular}{|c|c|c|c|c|c}
\multicolumn{2}{|c|}{$\begin{array}{c}\text { Total da } \\
\text { Amostra }\end{array}$} & \multicolumn{2}{c|}{$\begin{array}{c}\text { Menos de 18 } \\
\text { meses }\end{array}$} & \multicolumn{2}{c}{$\begin{array}{c}\text { Mais de 18 } \\
\text { meses }\end{array}$} \\
\hline Média & Moda & Média & Moda & Média & Moda \\
\hline 3,53 & 5 & 3,68 & 5 & 3,37 & 5 \\
\hline 3,41 & 5 & 3,63 & 5 & 3,19 & 3 \\
\hline 3,61 & 5 & 3,78 & 5 & 3,43 & 2 \\
\hline 3,08 & 2 & 3,25 & 2 & 2,89 & 2 \\
\hline 3,73 & 5 & 3,91 & 5 & 3,53 & 2 \\
\hline 3,45 & 5 & 3,69 & 5 & 3,19 & 3 \\
\hline 3,17 & 2 & 3,51 & 4 & 2,80 & 2 \\
\hline 2,55 & 1 & 2,79 & 4 & 2,29 & 1 \\
\hline 2,94 & 2 & 3,25 & 4 & 2,61 & 2 \\
\hline
\end{tabular}

Fonte: Indicadores adaptados de Damke et al. (2011) 


\section{SISTEMAS DE CONTROLE E ALINHAMENTO ESTRATÉGICO: UMA ANÁLISE DO EQUILÍBRIO \\ ENTRE AS ALAVANCAS DE SIMONS E O ALINHAMENTO COM A ESTRATÉGIA DE UMA INSTITUIÇÃO PÚBLICA DE ENSINO SUPERIOR \\ DOI: http://dx.doi.org/10.5007/1983-4535.2017v10n3p17}

O sistema de diagnóstico teve, em média, grau 3 na escala, o que demonstra que a sua presença não é efetivamente percebida. O resultado mais baixo ocorreu na penalização em caso de não atendimento da meta. Esse resultado não surpreende, pois, na área pública, os servidores têm estabilidade e a penalização em geral se dá por meio de processo administrativo oneroso e demorado.

Embora a média tenha um resultado abaixo do grau 4, a moda representando a resposta que mais apareceu, ficou no grau 5 em cinco indicadores. Destaca-se que a resposta que mais evidenciou-se quando questionado se a organização possui metas e objetivos claros foi concordo parcialmente. O interessante é que a instituição tem seus objetivos estabelecidos em lei própria e divulga em seu site institucional (unila.edu.br). Porém a alavanca de diagnóstico sugere que a comunicação e o esclarecimento sobre metas e objetivos precisa ser desenvolvido.

Tabela 5 Estatística descritiva do indicador negativo sistemas de limites

\begin{tabular}{l|c|c|c|c|c|c}
\multirow{2}{*}{ Sistemas de Limites } & \multicolumn{2}{c|}{$\begin{array}{c}\text { Total da } \\
\text { Amostra }\end{array}$} & \multicolumn{2}{c|}{$\begin{array}{c}\text { Menos de 18 } \\
\text { meses }\end{array}$} & \multicolumn{2}{c}{$\begin{array}{c}\text { Mais de 18 } \\
\text { meses }\end{array}$} \\
\cline { 2 - 7 } & Média & Moda & Média & Moda & Média & Moda \\
\hline $\begin{array}{l}\text { 1. A organização possui um código de ética } \\
\text { e de conduta. }\end{array}$ & 4,77 & 6 & 4,78 & 6 & 4,76 & 5 \\
\hline $\begin{array}{l}\text { 2. A organização divulga seu código de } \\
\text { ética e de conduta. }\end{array}$ & 3,43 & 2 & 3,54 & 2 & 3,32 & 2 \\
\hline $\begin{array}{l}\text { 3. Os limites e as regras a serem respeitados } \\
\text { são divulgados formalmente. }\end{array}$ & 3,39 & 2 & 3,49 & 2 & 3,29 & 1 \\
\hline $\begin{array}{l}\text { 4. A organização possui regras claras. } \\
\text { 5. Os limites quanto à liberdade/autonomia } \\
\text { são formalmente declarados. }\end{array}$ & 3,41 & 2 & 3,48 & 2 & 3,35 & 2 \\
\hline $\begin{array}{l}\text { 6. Os limites declarados pela organização } \\
\text { orientam os servidores, uma vez que } \\
\text { divulgam até que ponto podem chegar. }\end{array}$ & 3,12 & 2 & 3,28 & 2 & 2,96 & 2 \\
\hline $\begin{array}{l}\text { 7. O código de ética e de conduta divulga as } \\
\text { regras a serem seguidas na organização e as } \\
\text { sanções que serão sofridas, se essas regras } \\
\text { forem descumpridas. }\end{array}$ & 3,66 & 2 & 3,94 & 2 & 3,37 & 2 \\
\hline $\begin{array}{l}\text { 8. A instituição realiza, efetivamente, a } \\
\text { punição dos que transgridem as regras da } \\
\text { organização. }\end{array}$ & 3,55 & 4 & 3,41 & 4 & 3,69 & 5 \\
\hline $\begin{array}{l}\text { 9. Os superiores declaram publicamente os } \\
\text { limites a serem respeitados na organização. }\end{array}$ & 3,19 & 2 & 3,33 & 2 & 3,04 & 2 \\
\hline
\end{tabular}

Fonte: Indicadores adaptados de Damke et al. (2011) 


\section{SISTEMAS DE CONTROLE E ALINHAMENTO ESTRATÉGICO: UMA ANÁLISE DO EQUILÍBRIO \\ ENTRE AS ALAVANCAS DE SIMONS E O ALINHAMENTO COM A ESTRATÉGIA DE UMA INSTITUIÇÃO PÚBLICA DE ENSINO SUPERIOR \\ DOI: http://dx.doi.org/10.5007/1983-4535.2017v10n3p17}

Quanto à presença de limites, chama-se a atenção para a resposta mais frequente (concordo), com a afirmação sobre a instituição possuir código de ética. Foi o grau médio mais elevado entre os indicadores de limites. Porém, quando se avalia a divulgação e operacionalização desse código de ética, as respostas mais frequentes são de nível 2 (discordo). Percebe-se que os sistemas negativos têm níveis mais baixos de presença percebida. A causa desse efeito nos dois sistemas pode ser a mesma, ou seja, na área pública existem restrições legais quanto à penalização e à limitação.

\subsection{EQUILÍBRIO DAS ALAVANCAS}

Simons (1995) critica as metodologias de sistemas de controle que asseguram não haver surpresas. As organizações são dinâmicas, os controles equilibrados entre estímulos motivacionais e limites comportamentais pressupõe que surpresas não podem ser evitadas, mas a forma de lidar com elas pode ser controlada. No mesmo sentido, embora a instituição possa não adotar as alavancas propostas, não terá como negar a existência de valores centrais, riscos a serem evitados, incertezas estratégicas e variáveis críticas de desempenho. Os gerentes escolhem como irão acessar esses conceitos. Simons (1995) sugere que seja de maneira equilibrada, gerando limites que direcionem a missão, objetivos e estímulos que conduzam a busca de oportunidades e a inovação nos aspectos centrais da organização.

Figura 2 Presença média dos Controles

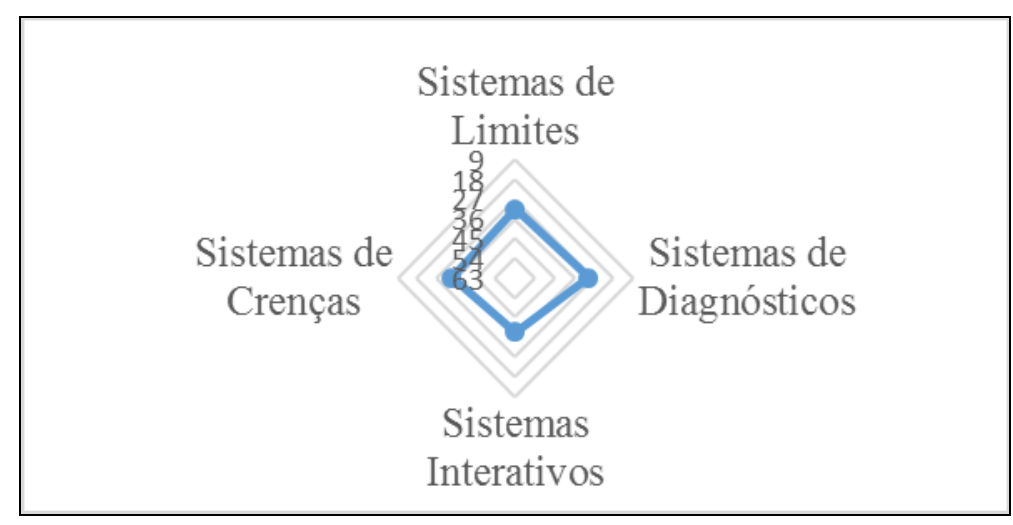

Fonte: Autores

A Figura 2 fornece uma medida visual e quantitativa da presença percebida dos sistemas de controle - o que auxiliará na análise do grau de equilíbrio existente entre as alavancas. A figura representa, em gráfico de radar, a soma das médias dos indicadores. O desenho esperado com alinhamento perfeito acertaria o centro do radar. Porém, infere-se que 


\section{SISTEMAS DE CONTROLE E ALINHAMENTO ESTRATÉGICO: UMA ANÁLISE DO EQUILÍBRIO \\ ENTRE AS ALAVANCAS DE SIMONS E O ALINHAMENTO COM A ESTRATÉGIA DE UMA INSTITUIÇÃO PÚBLICA DE ENSINO SUPERIOR \\ DOI: http://dx.doi.org/10.5007/1983-4535.2017v10n3p17}

a percepção sobre a presença do acesso dos gestores, por meio das alavancas, atinja um nível médio de percepção.

Por se tratar de sistemas que oferecem forças positivas e negativas, precisariam ser acessados de maneira equilibrada. Simons (1995) ensina que as técnicas de comando e controle não são mais suficientes em ambientes dinâmicos, onde a criatividade e a iniciativa dos funcionários são fundamentais para o sucesso do negócio. A proposta é que se controle e se monitore, mantendo os objetivos, mas que se estimule para que eles possam ser alcançados.

A Figura 2 permite a visualização da presença das alavancas que, no gráfico radar, demonstra que as somas das médias das quatro alavancas permanecem no mesmo grau, ou seja, considerando que cada alavanca possuía nove indicadores e o mínimo na escala é 1, temos 9 graus em cada camada. Esse resultado demonstra que, embora a percepção das alavancas seja modesta, o equilíbrio representa um fator positivo, pois os extremos poderiam conduzir a decisões de risco ou demasiadamente seguras e ainda sem resultados para o atingimento dos objetivos estratégicos, coadunando com a proposta de Simons (1995) sobre como os gerentes devem acessar os conceitos-chave.

Para analisar a correlação entre as alavancas de controle e a percepção do alinhamento estratégico, reduziram-se as variáveis em dimensões, conforme demonstrado na Tabela 4 . Na dimensão interativa, quando selecionados os nove indicadores, a análise de componente principal resulta em dois (Interativo 1 e 2). Isso significa que nem todos os componentes selecionados estavam correlacionados internamente.

Para possibilitar comparações na análise, bem como a avaliação do equilíbrio, excluiuse o oitavo indicador do sistema interativo: "a participação dos servidores com sugestões é importante para que as estratégias foquem a organização como um todo". Observa-se na Tabela 2 que o oitavo indicador apresenta média $(5,16)$ e moda $(6)$ - superiores aos demais e, por essa razão, apresentam-se na Tabela 4 os resultados das três diferentes combinações da dimensão interativo: 
Tabela 4 Correlação após redução dos indicadores

\begin{tabular}{l|c|c|c|c|c|c|c}
\hline rô de Spearman & $\begin{array}{c}\text { Alinha- } \\
\text { mento }\end{array}$ & Limites & $\begin{array}{c}\text { Diagnós- } \\
\text { tico }\end{array}$ & Crenças & $\begin{array}{c}\text { Intera- } \\
\text { tivos 1 }\end{array}$ & $\begin{array}{c}\text { Intera- } \\
\text { tivos 2 }\end{array}$ & $\begin{array}{c}\text { Interativo } \\
\text { sem oitavo } \\
\text { indicador }\end{array}$ \\
\hline Alinhamento & 1,000 & & & & & & \\
\hline Limites & $\mathbf{0 , 3 4 9 ^ { * * }}$ & 1,000 & & & & & \\
\hline Diagnóstico & $\mathbf{0 , 4 4 6 ^ { * * }}$ & $0,484^{* *}$ & 1,000 & & & & \\
\hline Crenças & $\mathbf{0 , 4 0 4}^{* *}$ & $0,478^{* *}$ & $0,444^{* *}$ & 1,000 & & & \\
\hline Interativos 1 & $\mathbf{0 , 3 0 5 ^ { * * }}$ & $0,415^{* *}$ & $0,499^{* *}$ & $0,364^{* *}$ & 1,000 & & \\
\hline Interativos 2 & $0,173^{*}$ & 0,021 & 0,038 & $0,186^{*}$ & $-0,073$ & 1,000 & \\
\hline $\begin{array}{l}\text { Interativos sem } \\
\text { oitavo } \\
\text { indicador }\end{array}$ & $0,292^{* *}$ & $\mathbf{0 , 4 1 4 ^ { * * }}$ & $\mathbf{0 , 4 9 9 ^ { * * }}$ & $\mathbf{0 , 3 4 2 ^ { * * }}$ & $\mathbf{0 , 9 9 6 ^ { * * }}$ & $-0,133$ & 1,000 \\
\hline
\end{tabular}

* A correlação é significativa no nível 0,05 (2 extremidades)

** A correlação é significativa no nível 0,01 (2 extremidades)

O resultado da correlação entre as alavancas e o alinhamento estratégico foi promissor. As dimensões de limites, diagnóstico, crenças, interativos 1 - e sem o oitavo indicador -, apresentaram correlação significativa a 0,01. Observa-se que apenas as combinações da dimensão inte $\neg$ ra $\neg$ tivos 2 - componente selecionado pelo software - apresentaram correlação fraca (rô $<0,30)$. As demais dimensões alcançaram correlação moderada $(0,3<$ rô $<0,7)$. É importante destacar, de acordo com Lira (2014), que as correlações não mostram necessariamente tendência linear, mas podem ser consideradas como índices de monotonicidade, ou seja, para aumentos positivos da correlação, aumentos no valor de $\mathrm{X}$ correspondem a aumentos no valor de $\mathrm{Y}$.

Considerando que há correlação entre as dimensões correspondentes aos sistemas de controle e o alinhamento, verifica-se a presença dos 5 elementos. O equilíbrio da percepção das 5 dimensões indica que avaliou-se o mesmo conceito e, além disso, que os indicadores utiliza $\neg$ dos têm condições favoráveis para comporem um sistema de controle que possa ser implantado pela instituição.

Schreyogg e Steimann (1987) ensinam que o controle estratégico é um processo, com o fim de avaliar se os planos estratégicos estão calibrados com os objetivos da instituição, em um determinado período de tempo. Ao que parece, a percepção dos servidores indica que os sistemas de controle propostos por Simons têm correlação significativa com a percepção do alinhamento estratégico e, portanto, podem ser utilizados para avaliar se os planos estratégicos estão calibrados com os objetivos institucionais. 
Elaborar um planejamento estratégico não é tarefa simples. Ao analisar os indicadores propostos, verifica-se que é quase imperceptível a probabilidade de a opinião do integrante sobre sua importância na instituição estar avaliando outra dimensão como, por exemplo, Comportamento.

Figura 3 Presença média das dimensões

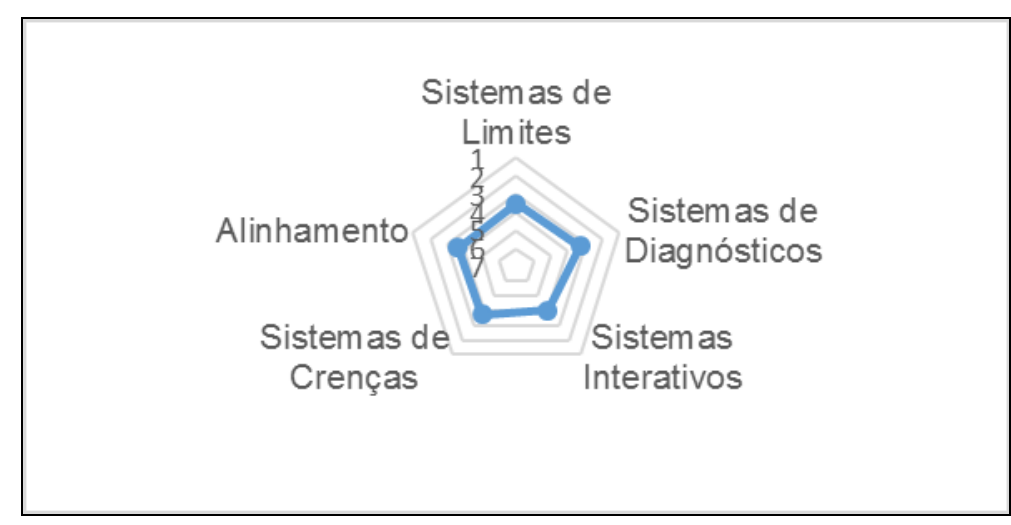

Fonte: Autores

Os indicadores interativos, que avaliaram a importância da participação de todos, tiveram a maior média das dimensões avaliadas. Isso direciona o item interativo para o centro do alinhamento estratégico perfeito. Observa-se na, figura 3, o alinhamento estratégico no mesmo nível das demais dimensões, indicando que os atributos extraídos da literatura estão avaliando os mesmos conceitos.

Essa avaliação é substancial para um administrador que pretende conhecer as variáveis que afetam o planejamento estratégico. No caso expressado, acessando os conceitos chaves, definidos por Simons (1995), por meio dos quatro sistemas propostos, o gestor poderá pressupor que o ganho em cada nível da alavanca representará também ganhos na percepção sobre o alinhamento estratégico.

Salienta-se que as dimensões utilizadas possuem correlação com a dimensão alinhamento estratégico, bem como os indicadores utilizados são qualificados para serem implantados na instituição, em resposta a contribuição adicional de avaliar os indicadores. Sugere-se que sejam revisados os indicadores interativos, pois, no aspecto de participação dos indivíduos na concepção do alinhamento estratégico, aparentemente o oitavo indicador apresentou tendência linear nesta organização. 


\section{CONSIDERAÇÕES FINAIS, LIMITAÇÕES E RECOMENDAÇÕES}

O estudo objetivou responder qual o grau em que cada uma das alavancas de controle, propostas por Simons (1995), estão presentes na UNILA e, além disso, como contribuição adicional, se os indicadores ope $\neg$ racionais propostos possibilitam uma avaliação do alinhamento estratégico. Para tal, aplicou-se o levantamento por meio eletrônico, para se compreender e analisar os indicadores utilizados.

No campo teórico, o estudo possibilitou uma avaliação empírica da correlação entre as alavancas de controle e o alinhamento estratégico. A amostra analisada apresentou correlação significativa e positiva do alinhamento estratégico com as quatro alavancas de controle. Os resultados sugerem que o aumento da presença das alavancas, embora moderadamente, afetam a percepção do alinhamento estratégico. Esse achado condiz com o argumento de Simons - o meta-equilíbrio das alavancas conduz ao alinhamento do planejamento estratégico.

Os valores centrais, riscos a serem evitados, incertezas estratégicas e variáveis críticas de desempenho existem independentemente da vontade dos gestores. Os resultados permitem aos gestores um caminho mais efetivo, na escolha dos indicadores que utilizarão para monitorar a organização. Os trinta e nove indicadores utilizados apresentaram confiabilidade de escala nos testes estatísticos. A contribuição gerencial, trazendo à baila indicadores testados, é relevante por proporcionar um caminho mais curto e assertivo para a instituição.

Os indicadores precisam permitir comparabilidade e visualizações das tendências no tempo. Gerenciar com mensuração significa utilizar a informação baseada em indicadores. Portanto, os indicadores precisam estar normalizados e fornecer dados confiáveis e relevantes aos objetivos da instituição. E, nesse sentido, a avaliação empírica é fundamental na escolha de indicadores de gestão.

TCU (2011) apontou como características essenciais de um indicador: validade, compa $\neg$ rabilidade, estabilidade, homogeneidade, praticidade, independência, confiabilidade, seletivi $\neg$ dade, compreensão, completude, economicidade, acessibilidade, tempestividade, objetividade, portabilidade, invariância de escala. A grande heterogeneidade do conjunto de indicadores, apresentada por seis Instituições Federais de Ensino Superior (IFES) auditadas, mostrou-se incapaz de, isoladamente, permitir conclusões sobre o desempenho das 


\section{SISTEMAS DE CONTROLE E ALINHAMENTO ESTRATÉGICO: UMA ANÁLISE DO EQUILÍBRIO \\ ENTRE AS ALAVANCAS DE SIMONS E O ALINHAMENTO COM A ESTRATÉGIA DE UMA INSTITUIÇÃO PÚBLICA DE ENSINO SUPERIOR \\ DOI: http://dx.doi.org/10.5007/1983-4535.2017v10n3p17}

instituições, o que torna ainda mais urgente, para outras instituições, a implantação de indicadores adequados.

Um grave erro é importar indicadores de outras organizações, sem fazer uma análise crítica e avaliação prévia de sua compreensão e aplicabilidade, no contexto da organização. O propósito principal da avaliação é orientar a instituição no aperfeiçoamento de suas atividades, permitir o acompanhamento e o alcance das metas e objetivos estratégicos, assim como, identificar melhorias, correções de problemas e necessidades de mudança.

Para responder a pergunta de pesquisa, foi apresentado o gráfico radar (Figura 1), que demonstrou a percepção dos respondentes sobre a utilização das alavancas. A soma da média dos indicadores operacionais ficou próxima do nível quatro em todos os sistemas. Isso indica uma percepção equilibrada do acesso às alavancas na instituição. A instituição está em fase de implantação. Portanto, este seria um momento interessante para a avaliação de cada indicador. A mensuração pode estabelecer adequações no planejamento estratégico e resultar em uma melhor calibragem com os objetivos. Um resultado equilibrado, ainda que em grau médio, significa que a instituição não apresenta forças negativas (limitadoras) maiores que as positivas (motivadoras), e, portanto, nenhuma alavanca é responsável pelo desalinhamento estratégico.

Os conceitos-chave valores centrais, riscos a serem evitados, incertezas estratégicas e variáveis críticas de desempenho estarão presentes, independentemente de os gestores acessálos por meio das alavancas, ou por qualquer outro modelo similar. Simons (1995) sugere que os sistemas de controle são importantes instrumentos para gerenciar mudanças, especialmente nos momentos de mudanças estratégicas, em que os gestores necessitem manter fronteiras de atuação com mecanismos formais de controle. Em razão das correlações identificadas, bem como a confiabilidade que apresentaram nos testes, conclui-se que os indicadores são efetivos para serem implantados, pois apresentam medidas úteis em relação ao alinhamento estratégico.

Outra perspectiva das informações obtidas permite identificar tanto os pontos fortes como os a desenvolver, permitindo o conhecimento sobre a própria instituição, o que possibilita as adequações das práticas de gestão universitária. No contexto da gestão contemporânea, o acompanhamento e constante mensuração podem ser considerados necessários, principalmente em razão da exigência de as universidades serem submetidas a processos de avaliação pelo Ministério da Educação (MEC). 
Dois pontos ofereceram limitações a esse estudo. Em primeiro lugar está o número de respondentes. $\mathrm{O}$ ideal seria uma avaliação censitária, porém, na área pública, isso se torna uma tarefa morosa, em razão da grande heterogeneidade de profissionais. O segundo limitador foi o número de questões sobre o alinhamento estratégico. As três questões quase não passaram no teste de confiabilidade de escala, o que poderia ser contornado com um número maior de indicadores sobre esta dimensão.

Recomenda-se, como sugestão de pesquisa futura, a realização do estudo em outras instituições de ensino superior, principalmente instituições públicas, para avaliar a correlação das alavancas com o alinhamento estratégico. Na replicação do estudo, outra sugestão seria utilizar mais indicadores sobre o alinhamento estratégico, preferencialmente na mesma proporção das demais dimensões, para resolver o problema de confiabilidade de escala, que pode ter sido um limitador do estudo. Sempre que possível, também é indicada a realização de censo, para evitar riscos de resultados enviesados.

\section{REFERÊNCIAS}

AKAO, Y. Desdobramento das diretrizes para o sucesso do TQM. Porto Alegre: Bookman, 1997.

ANTHONY, Robert N.; GOVINDARAJAN, Vijay. Sistemas de controle gerencial. São Paulo: Atlas, 2001.

BEUREN, Ilse Maria; ORO, Ieda Margarete. Relação entre estratégia de diferenciação e inovação, e sistemas de controle gerencial. Revista de Administração Contemporânea, v. 18 , n. 3, p. 285-310, 2014.

BUSHFIELD, S. The relationship between human capital and enterprising public services: a critical review of the literature and proposals for further research Paper presented to the Doctoral Track of the 9th International Conference on Human Resource Development, IESEG, Lille, France, 2008.

BRASIL, Lei $n^{\circ} .12 .189$ de 12 de janeiro de 2010. Dispõe sobre a Criação da Universidade da Integração Latina Americana - UNILA e dá outras providências. Disponível em:<http://www.planalto.gov.br/ccivil_03/_ato2007-2010/2010/lei/L12189.htm>. Acesso em 12 dez. 2015.

CINTRA, Yara Consuelo. A integração da sustentabilidade às práticas de controle gerencial das empresas no Brasil. 2011. Tese de Doutorado. Universidade de São Paulo. 
DAMKE, Elói Júnior; DA SILVA, Eduardo Damião; WALTER, Silvana Anita. Sistemas de controle e alinhamento estratégico: proposição de indicadores. Revista Eletrônica de Estratégia \& Negócios, v. 4, n. 1, p. p. 65-87, 2011.

DUCLÓS, L. C., SANTANA L. S. Ciclo estratégico da informação: como colocar a TI no devido lugar. Curitiba: Champagnat, 2004.

HAIR, Joseph F. et al. Análise multivariada de dados. Bookman Editora, 2005.

LIRA, Sachiko Araki. Análise de correlação: abordagem teórica e de construção dos coeficientes com aplicações. (Dissertação) - Universidade Federal do Paraná, Paraná, p. 10, 2004.

KRAVCHUK, Robert S.; SCHACK, Ronald W. Designing effective performancemeasurement systems under the Government Performance and Results Act of 1993. Public Administration Review, v. 56, n. 4, p. 348-358, 1996.

LABOVITZ, G.; ROSANSKY, V. The Power of Alignment: how great companies stay centered and accomplish extraordinary things. EUA: John Wiley e Sons, 1997.

MALHOTRA, N.K. Pesquisa de Marketing: uma orientação aplicada. 4. ed. Porto Alegre: Bookman, 2006.

MOORE, M. H. Creating Public Value: Strategic Management in Government. London: Harvard University Press.

OTLEY, D. Performance management: a framework for management control systems research. Management accounting research, v. 10, p. 363-382, 1999.

RAUPP, F. M.; BEUREN, I. M. Metodologia da pesquisa aplicável às ciências sociais. In: BEUREN, I. M. (org.). Como elaborar trabalhos monográficos em contabilidade: teoria e prática. 3. ed. São Paulo: Atlas, 2009.

SCHREYÖGG, Georg; STEINMANN, Horst. Strategic control: a new perspective. Academy of Management Review, v. 12, n. 1, p. 91-103, 1987.

SIMONS, R. Levers of control: how managers use innovative control systems do drive strategic renewal. Boston: Harvard Business School, 1995.

STOKER, G. 2006. Public Value Management: A New Narrative for Networked Governance? American Review of Public Administration, n. 1, p. 41-57.

TCU. Tribunal de Contas da União. Decisão no 408/2002. Plenário. Auditoria Operacional. Relatório consolidado. Universidades federais. UNB. FUAM. UFGO. UFPE. UFRJ. UFRS. Elaboração de diagnóstico na área de ensino público superior. 